\title{
A exclusão social dos moradores da área de ressaca do bairro do Congós no município de Macapá.
}

\author{
Dirley Furtado da Silva \\ Universidade Estadual do Ceará - UECE \\ Hermano Machado Ferreira Lima \\ Universidade Estadual do Ceará - UECE
}

\begin{abstract}
Resumo
O presente estudo traz como tema central a exclusão social dos moradores da área de ressaca do bairro do Congós no município de Macapá. Busca investigar a exclusão social dos moradores da área de ressaca do bairro do Congós, tendo como questões norteadoras, a situação socioeconômica dos moradores da área de ressaca do bairro do Congós; a atuação do poder público nas áreas de ressaca do município de Macapá; a atuação dos movimentos sociais na área de ressaca do bairro do Congós; a compreensão da percepção do morador da área de ressaca do bairro do Congós quanto a sua realidade. Com isso o estudo buscou investigar as formas de exclusão social que afetam os moradores da área de ressaca do bairro do Congós no município de Macapá. Como resultado da investigação, detectamos as seguintes formas de exclusão social: exclusão econômica, exclusão educacional, exclusão por alienação, exclusão cultural, exclusão política e exclusão meritocrática. Referente às categorias de análise, partimos das seguintes: exclusão social (Souza, 2009); Educação (Bourdieu, 2006); participação social (Gohn, 2003); alienação (Marx, 2008) e Estado (Weber, 1991). Em relação ao trabalho de campo da pesquisa, foram realizados vários momentos: levantamento bibliográfico; entrevistas com representantes do poder público e dos movimentos sociais do bairro do Congós; aplicação de formulários às famílias da área de ressaca do bairro do Congós.
\end{abstract}

Palavra-chave exclusão social; área de ressaca; estado; participação social; educação; alienação.

\begin{abstract}
The present study has as a central theme the social exclusion of residents of the hangover area of the Congós neighborhood in the municipality of Macapá. It seeks to investigate the social exclusion of the residents of the hangover area of the Congós neighborhood, having as guiding questions, the socioeconomic situation of the residents of the hangover area of the Congós neighborhood; the performance of public power in the hangover areas of the municipality of Macapá; the performance of social movements in the hangover area of the
\end{abstract}


Congós neighborhood; the understanding of the residents' perception of the hangover area of the Congós neighborhood as to their reality. Thus, the study sought to investigate the forms of social exclusion that affect residents of the hangover area of the Congós neighborhood in the municipality of Macapá. With the result of the investigation, we detected the following forms of social exclusion: economic exclusion, educational exclusion, exclusion by alienation, cultural exclusion, political exclusion and meritocratic exclusion. Regarding the categories of analysis, we start with the following: social exclusion (Souza, 2009); Education (Bourdieu, 2006); social participation (Gohn, 2003); alienation (Marx, 2008) and state (Weber, 1991). In relation to the field work of the research, several moments were realized: bibliographical survey; interviews with representatives of the public power and of the social movements of the district of the Congós; application of forms to the families of the hangover area of the Congós neighborhood.

Key-word social exclusion, hangover area, State, social participation, education, alienation.

\section{Introdução}

Uma visão mais atualizada do conceito de desenvolvimento econômico e que vem sendo adotada pela Organização das Nações Unidas (ONU) a partir de 1990 é a de Desenvolvimento Humano.

Nesta perspectiva, o conceito de Desenvolvimento Humano está ancorado em três bases fundamentais: Longevidade, Educação e Renda Monetária. A longevidade é aferida pela esperança de vida ao nascer, que, dadas as circunstâncias atuais, uma criança teria em determinado país, estado ou município. Em termos mais pragmáticos, seria a idade em que, na média, as pessoas morrem nos lugares onde escolheram para viver.

A segunda âncora de apoio do conceito de Desenvolvimento Humano é o estoque de educação acumulado por uma sociedade. Este estoque seria aferido pelo percentual de adultos (maiores de quinze anos) alfabetizados e pelos percentuais de matrículas nas escolas dos diferentes níveis.

0 terceiro suporte do conceito da $\mathrm{ONU}$ de desenvolvimento humano é a renda média. Não se conceberá desenvolver sem prover condições de trabalho e de remuneração digna para as populações.

Para Gomes (2002), as mudanças políticas e econômicas ocorridas no estado do Amapá nas duas últimas décadas têm alterado significativamente a configuração espacial da capital do Estado, a cidade de Macapá.

A transformação de Território do Amapá para uma Unidade Federativa (Estado), através da Constituição Federal de 1988, e a criação da Área de Livre Comércio de Macapá e Santana (Decreto Federal $\mathrm{n}^{\circ}$ 8.387, de 30/12/91), foram os principais eventos que colaboraram tanto para o aumento populacional do Estado do Amapá, quanto para a expansão da malha urbana de Macapá provocada por um considerável contingente de migrantes que aportaram as cidades de Macapá e Santana, principalmente.

Segundo o IBGE (2010), o Estado do Amapá tem uma população aproximada de 669.956 habitantes, sendo que a capital Macapá possui o número estimado de 398.204 habitantes, ou seja, cerca de $60 \%$ dos moradores do Estado vivem na Capital. 
Segundo IBGE (2010), o número estimado de pessoas residentes nas áreas de ressacas no município de Macapá é de 63.771, o equivalente a $16 \%$ de seus habitantes.

Pelo exposto, o estudo teve como indagação principal a seguinte pergunta de partida: quais as formas de Exclusão Social que afetam os moradores da área de ressaca do bairro do Congós no município de Macapá/AP?

O estudo tem como objetivo geral Investigar a Exclusão Social dos Moradores da Área de Ressaca do Bairro do Congós no Município de Macapá, tendo como objetivos específicos a averiguação da situação socioeconômica dos moradores da área; avaliar a atuação do poder público nas áreas de ressaca do município de Macapá; investigar a atuação dos movimentos sociais atuantes na área e compreender a percepção dos moradores da área estudada sobre sua realidade.

Em relação às categorias de análise, partimos das seguintes: Exclusão Social (Souza, 2009); Educação (Bourdieu, 2006); Participação Social (Gohn, 2003); Alienação (Marx, 2008) e Estado (Weber, 1991).

Em relação ao trabalho de campo da pesquisa, no primeiro momento foi realizado um levantamento bibliográfico sobre o tema trabalhado, no sentido de adquirir embasamento teórico para melhor compreender o referido tema. Esse levantamento foi realizado nas bibliotecas das faculdades e universidades da cidade de Macapá, como também via internet e livrarias. No segundo momento foi realizada uma pesquisa de campo junto aos moradores da área de ressaca do bairro do Congós, por meio da coleta de dados empíricos, como também entrevistas com representantes do poder público e representantes dos movimentos sociais do bairro do Congós.

\section{A ocupação das áreas de ressaca no município de Macapá}

Após 45 anos de ser admitido como território, o Amapá passa por outra transformação em 1988 quando por meio da Constituição brasileira promulgada naquela época foi elevado à condição de estado.

Segundo Andrade (2005), essa transformação do então território em estado, efetivado a partir de 1988, possibilitou que novas oportunidades de trabalho fossem ofertadas, principalmente na construção civil, o que influenciou numa intensa movimentação populacional para o Estado.

Segundo Neri (2004), o processo de ocupação das áreas de ressaca na cidade de Macapá começou por volta da década de 1950 . No entanto, é a partir da segunda metade da década de 1980 que este processo de ocupação se intensifica, fazendo com que a alteração na estrutura dessas áreas acontecesse de forma cada vez mais acelerada.

\section{O bairro do Congós e sua área de ressaca}

Segundo o IBGE (2010), o bairro do Congós é o quinto bairro mais populoso de Macapá, com mais de 18 mil moradores, onde aproximadamente 19\% desses moradores vivem em área de ressaca. 
O bairro do Congós situado na Zona Sul da Capital, foi criado na década de 1990, depois de ter parte da área invadida. Apesar de ser cercado por áreas de ressacas (ocupadas irregularmente), o bairro tem boa infraestrutura: com escolas, posto de saúde, arena poliesportiva, CIOSP (Centro Integrado de Operações em Segurança Pública) e partes das avenidas asfaltadas.

O Congós se confunde com o bairro Novo Buritizal, dada a sua proximidade, mas no mapa da Cidade é na Av. Saúde Pimentel que começa o bairro, indo até a $24^{a}$ Avenida. 0 nome "Congós" faz referência ao antigo dono do lugar, Benedito Lino do Carmo, conhecido popularmente como "Seu Congó". Descendente de escravos, Seu Congó morou por muito tempo no bairro, onde vivia da agricultura e criação de gado. Elísia Congó (neta legítima) revela um pouco desta história: "0 nome do bairro era Araçás e fazia divisa com a Fazendinha, aquela área todinha era do vô Congó e ele cedia para as pessoas fazerem roça e tinha a criação de gado".

Quem também chegou ao bairro para morar com a família foi Dona Marizete Santos. Ela lembra como eram as coisas, antes das mudanças feitas, e vem acompanhando há 29 anos: "Era só mato e só tinham duas casas. Aqui tinha a fazenda do Seu Alípio e a do Seu Moraes. Tinha muita roça de mandioca, mucajazeiro e o campo, somente isso. Foram tendo as invasões, criando caminhos e assim a direção das ruas.".

Nadison Siqueira há 15 anos reside no bairro e recorda das dificuldades de antes e apela para que os trabalhos de melhorias continuem: "Tinha muita dificuldade. Ônibus não entrava... Eram poucas avenidas com asfalto. Hoje o bairro mudou muito, a maioria das avenidas já está asfaltada e faltam ainda coisas para o Poder Público concluir no nosso bairro" (programa Fala Comunidade TV/AMAPÁ, 2012).

Figura 1- área de ressaca do bairro do Congós

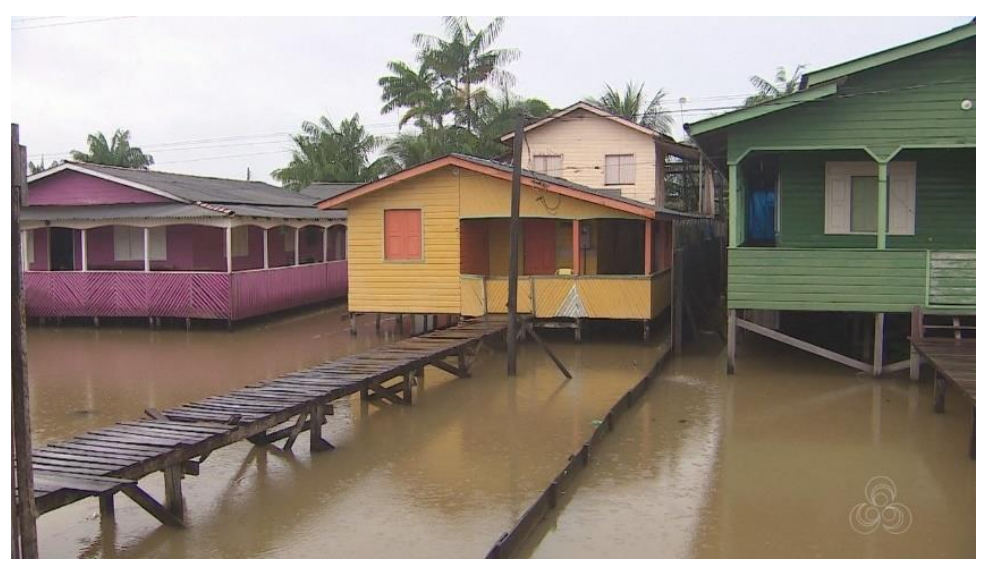

Fonte: G1 AMAPÁ

Quanto ao nível de escolaridade dos moradores da área de ressaca do bairro do Congós, somando os níveis de não alfabetizados, alfabetizados e fundamental, temos $41 \%$, nível médio $50 \%$, nível superior $11 \%$ e $0 \%$ de pós-graduação, ou seja, temos um sério quadro de exclusão educacional envolvendo a maioria dos moradores. 


\section{Gráfico 1 - Nível de escolaridade}

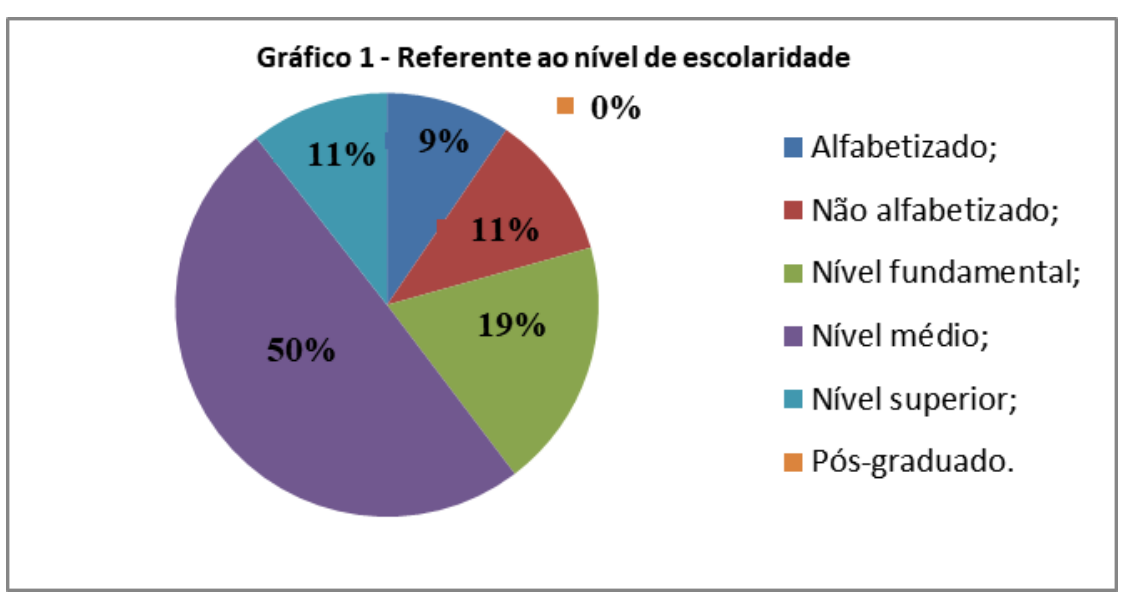

Fonte: pesquisa de campo realizada em maio/2019.

Para Durkheim (1978), as práticas educativas não são fatos isolados uns dos outros; ao contrário, para uma mesma sociedade, estão ligados num mesmo sistema em que todas as partes concorrem para um fim único: é o sistema de educação próprio desse país e desse tempo. (p.61).

Quanto a participação social dos moradores da área de ressaca do bairro do Congós, observamos um total desinteresse por parte da grande maioria dos informantes, $68 \%$ disseram não participar de nenhum movimento organizado, ou seja, temos aqui um grave quadro de exclusão política que envolve a maioria dos moradores.

\section{Gráfico 2 - Participação social}

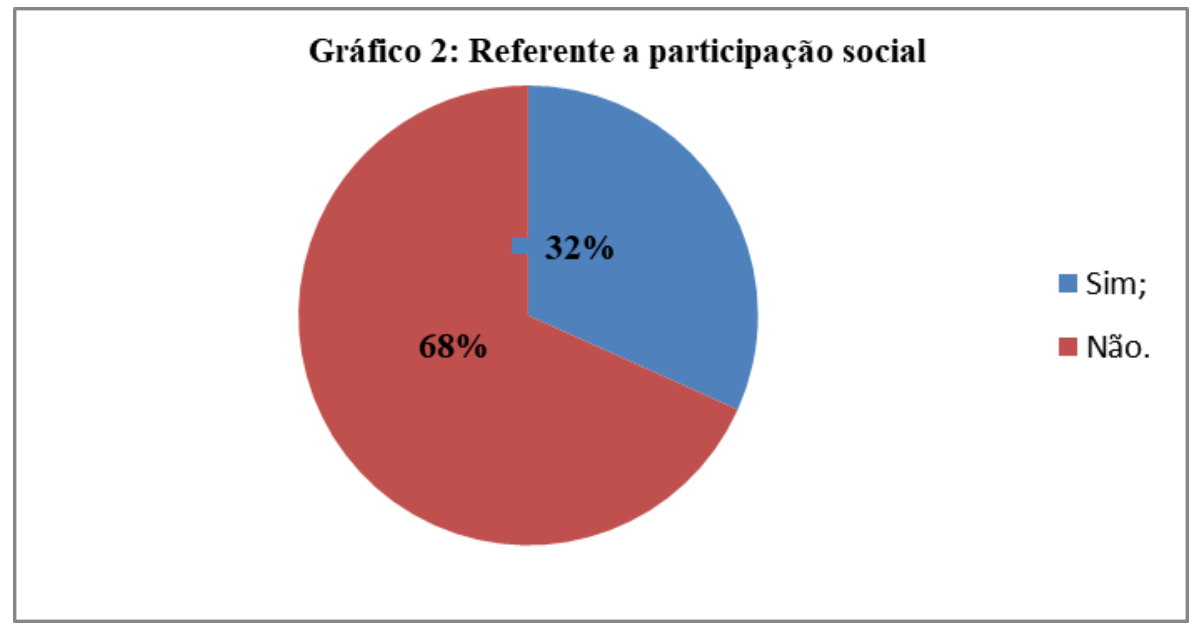

Fonte: pesquisa de campo realizada em maio/2019.

Para Demo (1998), a maneira de ver os problemas da exclusão, da pobreza ou da desigualdade tratados como temas interpenetrados está na relação estabelecida entre a carência material e a pobreza política, sendo a primeira vista como a camada mais externa e superficial de um processo cuja base está nesta última. 
O conceito de Demo de pobreza política diz respeito à desigualdade, que se estabelece por meio de relações de poder:

Entendemos por pobreza política a dinâmica central do fenômeno chamado pobreza e que privilegia a dimensão da desigualdade. Assim, ser pobre não é tanto 'ter' menos (carente), mas 'ser' menos (desigual).

Quanto à percepção dos moradores da área de ressaca do bairro do Congós, 57\% dos informantes dizem gostar de morar na área de ressaca, esse quadro nos mostra uma clara exclusão por alienação, vivenciada pela maioria dos moradores.

\section{Gráfico 3 - Local de moradia}

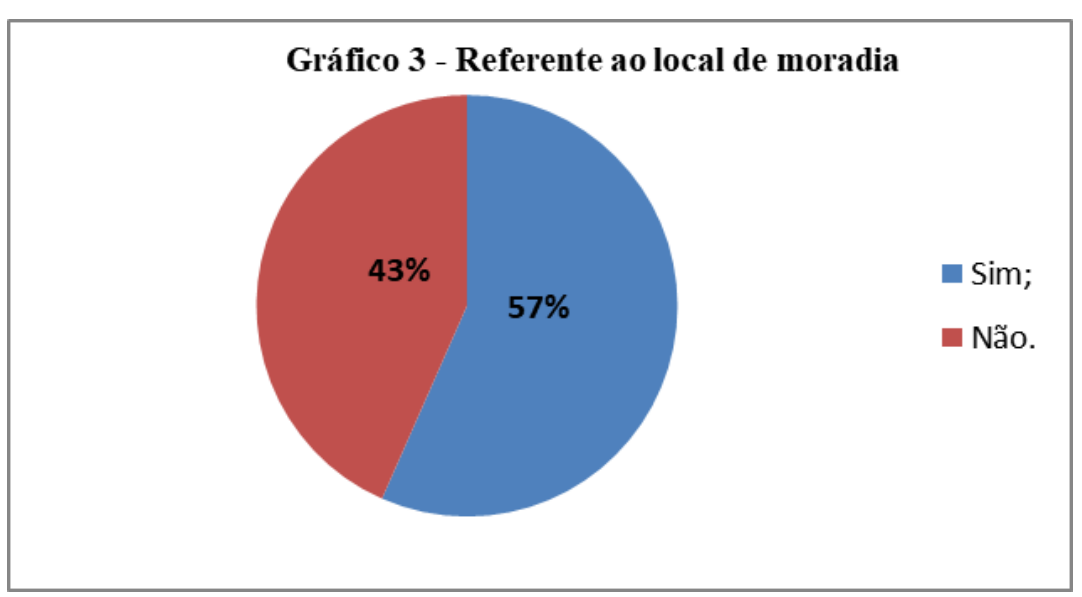

Fonte: pesquisa de campo realizada em maio/2019.

Ainda quanto a percepção dos moradores da área de ressaca do bairro do Congós, $66 \%$ dos informantes dizem não se sentir injustiçados ou excluídos da sociedade, esse quadro nos mostra também a exclusão por alienação, ou seja, a incapacidade de se perceber excluído(a), vivenciada pela maioria dos moradores.

\section{Gráfico 4 - Percepçãode injustição e exclusão}

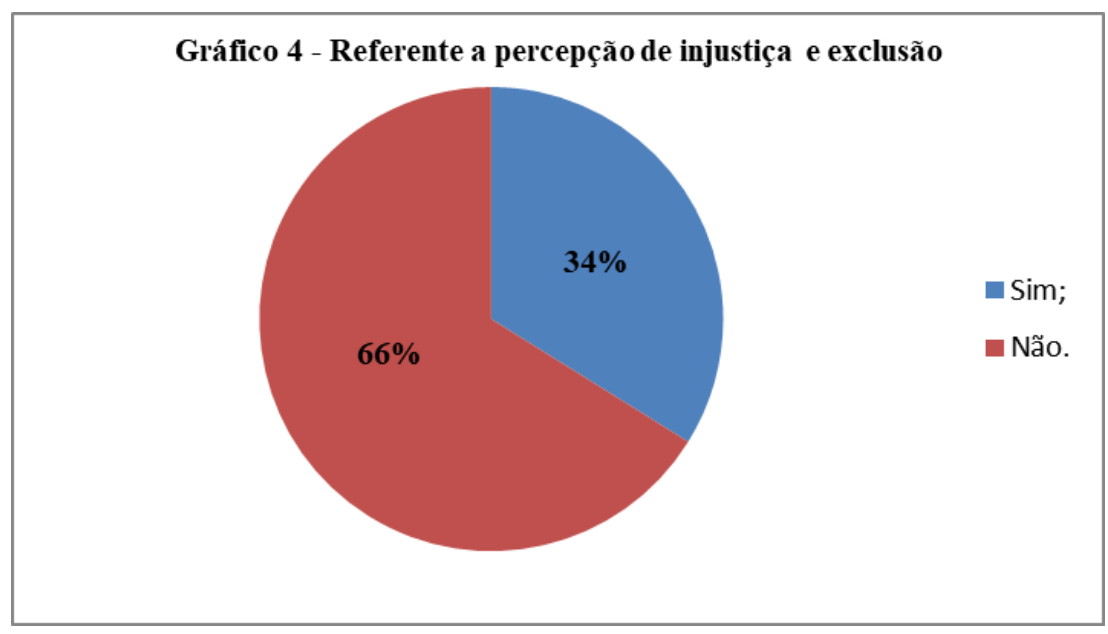

Fonte: pesquisa de campo realizada em maio/2019. 
Ainda quanto a percepção dos moradores da área de ressaca do bairro do Congós, $47 \%$ dos informantes dizem achar a exclusão social uma situação natural e $24 \%$ dizem ser vontade de Deus, uma constatação da exclusão por alienação, ou seja, a falta de percepção dos motivos da exclusão, vivenciada pela maioria dos moradores.

\section{Gráfico 5 - Percepção de realidade}

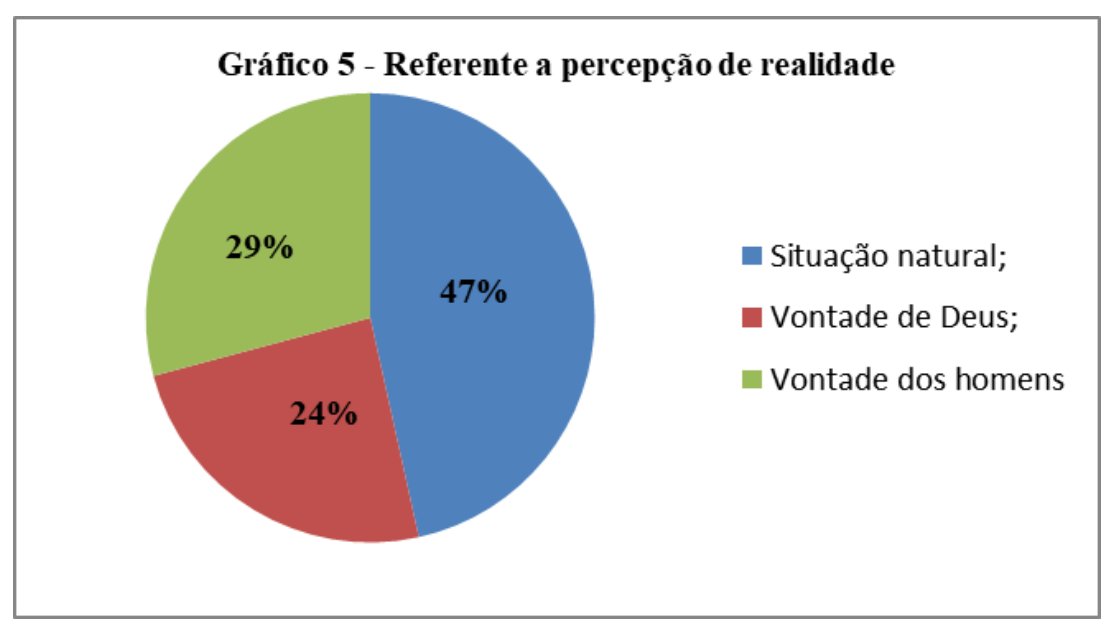

Fonte: pesquisa de campo realizada em maio/2019.

Segundo Marx (2008), o trabalho só produz mercadorias, ele se produz e produz o operário enquanto mercadoria, ou seja, o objeto que o trabalho produz seu produto afrontao como um ser estranho, como um poder independente do produtor. A atualização do trabalho é sua objetivação. Para a economia, esta atualização do trabalho aparece para o operário como a perda de sua realidade, a objetivação, como a perda do objeto ou sua escravização a ele, apropriação, como alienação ou desintegração.

Quanto a união dos moradores em busca de melhorias para os problemas vivenciados na área de ressaca do bairro do Congós, $62 \%$ dos informantes dizem não haver, isso nos mostra uma exclusão cultural, vivenciada pela maioria dos moradores.

\section{Gráfico 6 - A união dos moradores}

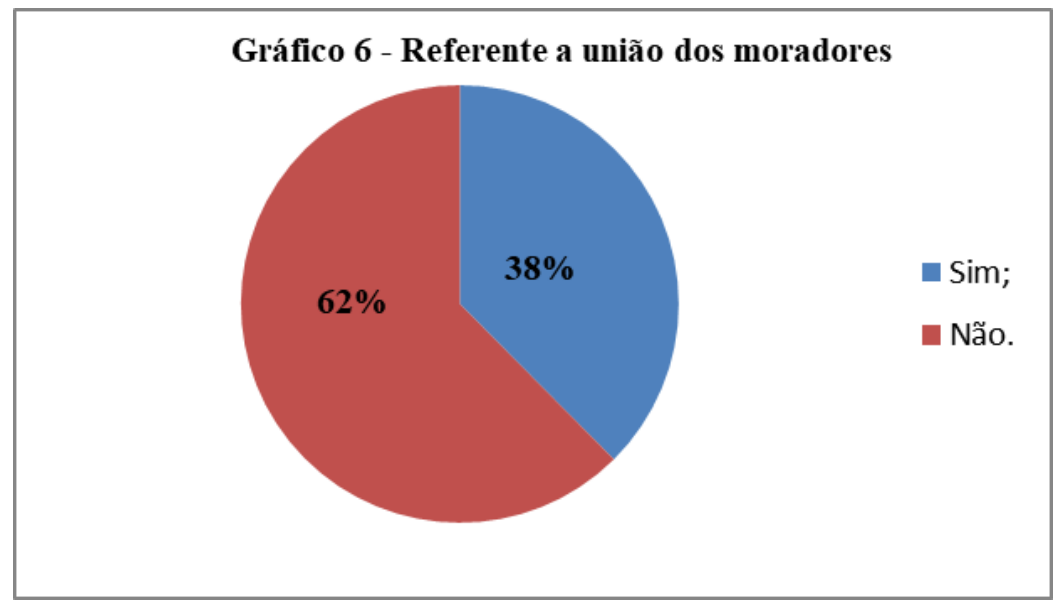

Fonte: pesquisa de campo realizada em maio/2019. 
Para Souza (2009), o processo de modernização brasileiro constitui não apenas as novas classes sociais modernas que se apropriam diferencialmente dos capitais cultural e econômico. Ele constitui também uma classe inteira de indivíduos, não só sem capital cultural nem econômico em qualquer medida significativa, mas desprovida, esse é o aspecto fundamental, das precondições sociais, morais e culturais que permitem essa apropriação.

Para Silver (1994), a exclusão social é compreendida como deficiência de solidariedade, isto é, como quebra do vínculo social entre indivíduo e sociedade, especialmente quanto à orientação cultural e moral.

Quanto a melhoria de vida dos moradores da área de ressaca do bairro do Congós, $44 \%$ dos informantes dizem ser de responsabilidade individual, ou seja, a mobilidade social depende do esforço próprio, 30\% dizem ser responsabilidade do poder público e sociedade e apenas $26 \%$ dizem depender do conjunto da sociedade, isso nos mostra uma exclusão por meritocracia, vivenciada pela maioria dos moradores.

\section{Gráfico 7 - Melhoria de vida}

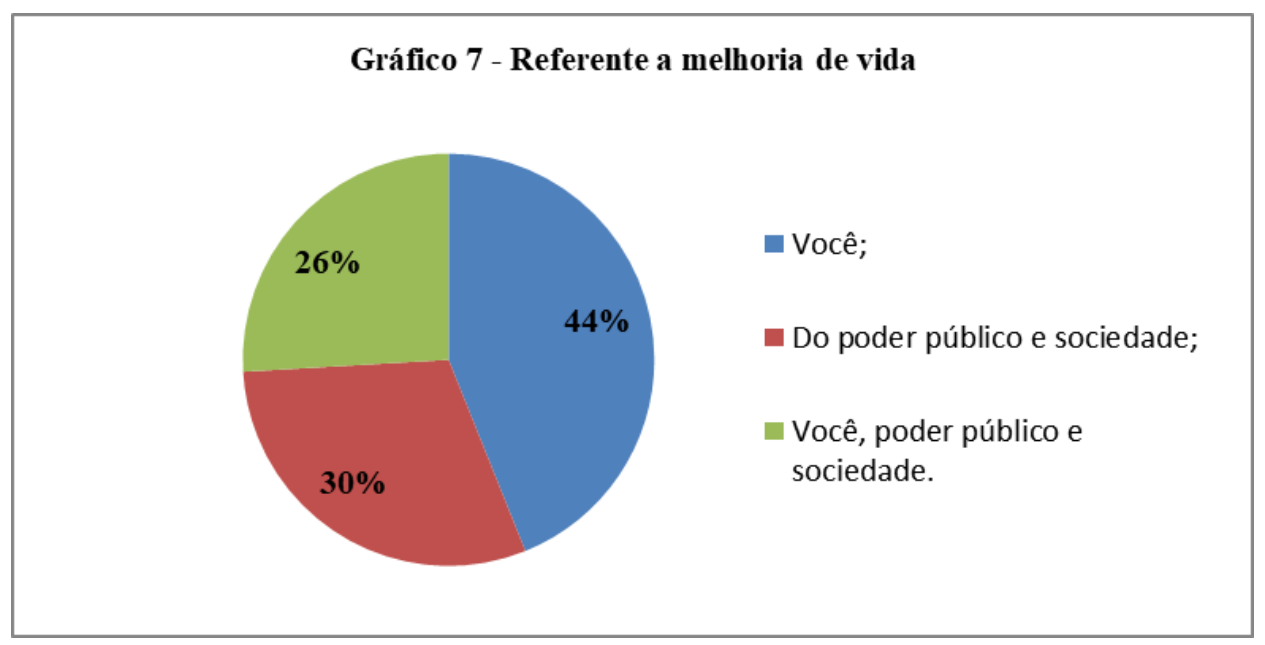

Fonte: pesquisa de campo realizada em maio/2019.

Para Souza (2009), na classe média a cegueira da visão redutoramente economicista do mundo é ainda mais visível. Essa classe social, ao contrário da classe alta, se reproduz pela transmissão afetiva, invisível, imperceptível porque cotidiana e dentro do universo privado da casa, das precondições que irão permitir aos filhos dessa classe competir, com chances de sucesso, na aquisição e reprodução de capital cultural.

Quanto a questão econômica dos moradores da área de ressaca do bairro do Congós, observamos que $62 \%$ das famílias ganham até dois salários mínimos, sendo que $27 \%$ ganham a baixo de um salário mínimo e apenas 11\% ganham até quatro salários, ou seja, há uma enorme exclusão econômica envolvendo a maioria dos moradores. 


\section{Gráfico 8 - Renda familiar}

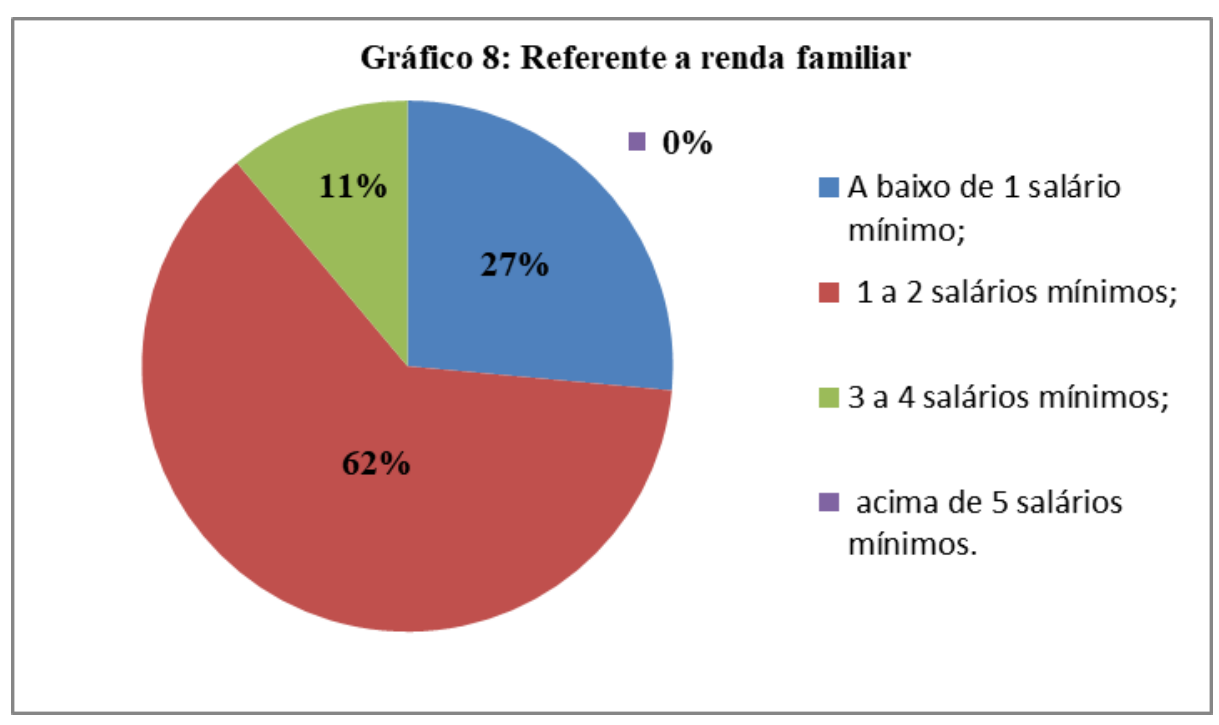

Fonte: pesquisa de campo realizada em maio/2019.

Segundo Souza (2009), a crença fundamental do economicismo é a percepção da sociedade como sendo composta por um conjunto de homo economicus, ou seja, agentes racionais que calculam suas chances relativas na luta social por recursos escassos, com as mesmas disposições de comportamento e as mesmas capacidades de disciplina, autocontrole e autoresponsabilidade. Nessa visão distorcida do mundo, o marginalizado social é percebido como se fosse alguém com as mesmas capacidades e disposições de comportamento do indivíduo da classe média. Por conta disso, o miserável e sua miséria são sempre percebidos como contingentes e fortuitos, um mero acaso do destino, sendo a sua situação de absoluta privação facilmente reversível, bastando para isso uma ajuda passageira e tópica do Estado para que ele possa "andar com as próprias pernas". Essa é a lógica, por exemplo, de todas as políticas assistenciais entre nós.

\section{Considerações Finais}

A Organização das Nações Unidas (ONU), em seu relatório de desenvolvimento humano de 1994, estabelece que, "a menos que as sociedades reconheçam que a sua verdadeira e real riqueza é o seu povo, uma obsessão excessiva com a criação de riqueza material pode obscurecer o seu último e fundamental objetivo que é o enriquecimento das suas próprias vidas" (HUMAN DEVELOPMENT REPORT, 1994, p. 16).

A investigação sobre a exclusão social dos moradores da área de ressaca do bairro do Congós, nos levou a conhecer diferentes visões de autores que tratam da temática da exclusão social, de maneira especial autores que investigaram as áreas de ressaca no município de Macapá, dentre os quais podemos citar: Neri (2004); Porto (2000); Moser (1996); Portilho (2006); Serrão e Lima (2013); Pereira, Souza e Silva (2015); Scheibe (2018).

Segundo IBGE (2010), o número estimado de pessoas residentes nas áreas de ressacas no município de Macapá é de 63.771, o equivalente a $16 \%$ de seus habitantes. 
Segundo pesquisa de campo realizada em maio de 2019, o bairro do Congós possui aproximadamente 1.699 famílias vivendo em área de ressaca.

$\mathrm{Na}$ visão dos citados autores nesta pesquisa, alguns pontos em comum são percebidos tais como: falta de planejamento do poder público para tratar a questão da ocupação das áreas de ressaca em Macapá; áreas de ressaca como locais impróprios para habitação; situação desumana dos moradores da área de ressaca, os quais vivem sem as mínimas condições de dignidade.

A partir da visão desses autores e suas constatações, pode-se concluir que os moradores da área de ressaca do município de Macapá são "excluídos socialmente", ou seja, não usufruem de condições mínimas de sobrevivência.

A partir dessa constatação é que o estudo procurou descobrir: quais as formas de exclusão social que afetam os moradores da área de ressaca do bairro do Congós no município de Macapá?

Referente às entrevistas dos representantes do poder público, podemos tirar algumas conclusões: falta de planejamento do poder público quanto a ocupação das áreas de ressaca do município de Macapá; falta de unidade das esferas municipal, estadual e federal, na busca por solução para a situação dos moradores das áreas de ressaca em Macapá, de maneira especial referente ao programa "Minha Casa, Minha Vida" do governo federal, pois nos últimos anos o programa entregou em Macapá, mais de oito mil moradias, as quais não foram direcionadas para as famílias das áreas de ressaca de Macapá.

Segundo juiz federal João Bosco, os governos estadual e municipal buscam "paliativos", mas não resolvem definitivamente o problema.

Ainda segundo o juiz, os agentes políticos não têm interesse em resolver o problema dos "bolsões de miséria", devido o "curral eleitoral" que os mesmos representam.

Quanto às entrevistas com os representantes dos movimentos sociais do bairro do Congós, podemos destacar: dificuldade em envolver os moradores da área de ressaca nos movimentos; dificuldade na unidade dos movimentos; dificuldade na relação com o poder público; falta de uma atuação mais forte nas lutas coletivas.

Quanto a questão dos agentes políticos, todos foram unânimes em afirmar que não há interesse em resolver os problemas dos "bolsões de miséria", devido os "currais eleitorais".

Como resposta à pergunta de nossa pesquisa, percebemos várias formas de exclusão social que afetam os moradores da área de ressaca do bairro do Congós, as quais já foram devidamente explicadas anteriormente: exclusão econômica; exclusão educacional; exclusão política; exclusão por alienação; exclusão cultural e exclusão por meritocracia.

Ao término deste trabalho, conseguimos perceber o quanto a educação é importante para a autonomia da sociedade; o quanto a sociedade civil precisa avançar no processo de organização e participação social; o quanto o sistema capitalista nos individualiza.

Esperamos que esse trabalho sirva de motivação para outros estudos, os quais possam aprofundar a temática da exclusão social. 


\section{Referências bibliográficas}

ANDRADE, Rosemary Ferreira de. Malária e migração no Amapá: projeção espacial num contexto de crescimento populacional. Belém: NAEA, 2005.

DURKHEIM, E.Educação e Sociologia. 11. ed. São Paulo: Melhoramentos, 1978.

DEMO, Pedro. Charme da exclusão social. Campinas: Autores Associados, 1998. In: Pobreza da pobreza. Petrópolis: Vozes, 2003.

DRUMMOND, José Augusto; PEREIRA, Mariângela de Araújo P. Amapá nos tempos do manganês: um estudo sobre o desenvolvimento de um estado amazônico - 1943-2000. Rio de Janeiro: Garamond, 2007.

GOMES, P. C. C. A condição urbana: ensaios de geopolítica da cidade. Rio de Janeiro: Bertrand, 2002.

GOHN, M. G. Conselhos Gestores e Participação Sociopolítica. São Paulo: Cortez, 2003.

INSTITUTO BRASILEIRO DE GEOGRAFIA E ESTATÍSTICA. Censos Demográficos 2010. Rio de Janeiro: IBGE, 2010. Disponível em: <http://www.censo2010.ibge.gov.br>. Acesso em: 10 ago.2011.

LEMOS, José de Jesus Sousa. Mapa da exclusão social no Brasil: radiografia de um país assimetricamente pobre. 3. ed. Fortaleza: Banco do Nordeste do Brasil, 2012.

MACIEL, N.C. Ressacas do Amapá: diagnóstico preliminar - propostas de recuperação, preservação e uso sustentado. Macapá: SEMA/AP, 2001.

MARX, Karl. 0 Capital. Tradução e condensação de Gabriel Deville. 3.ed. Bauru, SP: EDIPRO, 2008.

NERI, S. H. A. A utilização das ferramentas de geoprocessamento para identificação de comunidades expostas a hepatite A nas áreas de ressacas dos municípios de Macapá e Santana/AP. 2004. 173f. Dissertação (Mestrado em Engenharia Civil/Recursos Hídricos) - Coordenação dos Programas de Pós-Graduação em Engenharia, Universidade Federal do Rio de Janeiro, Rio de Janeiro, 2004.

NOGUEIRA, Maria A. Bourdieu e a Educação. 2. ed. Belo Horizonte: Graal. 1985.

PEREIRA, Ana Caroline Bonfim; SOUSA, Joice Cunha de ; SILVA, Ricardo Teixeira da. Desigualdade social, áreas de ressaca e locais perigosos em Macapá/AP. Macapá:[s.n], 2015.

PORTILHO Ivone dos Santos. Áreas de Ressaca e Dinâmica Urbana em Macapá/AP. Macapá:[s.n], 2006.

PORTO, J. R. Os territórios federais e sua evolução no Brasil. Revista Presença, Porto Velho, v.4, n. 16, p.33-37,2000.

PROGRAMA DAS NAÇÕES UNIDAS PARA O DESENVOLVIMENTO. Brasília: PNUD, 2018.

SCHEIBE Roberta. Violências Transparentes no Cotidiano do Conjunto Habitacional. In:

SCHERER-WARREN, I. Apresentação - Dossiê: movimentos sociais. Sociedade e Estado, Brasília, v. 21, n.1, p. 13-16, jan./abr., 2006.

SOUZA, Jessé. A Ralé Brasileira: quem é e como vive. Belo Horizonte : EdUFMG, 2009. 
SILVER, Hilary. Exclusión social y solidaridad social: tres paradigmas. Revista Internacional Del Trabajo, v.113, n.5-6, p.607-662, 1994.

SERRÃO, Sybelle Lima; LIMA, Ricardo Ângelo Pereira de. Áreas alagadas em Macapá: estudo de caso Bairro do Araxá. Artigo visa abordar as discussões travadas a cerca da ocupação de área alagadas no município de Macapá, especificamente no bairro do Araxá. Macapá:[s.n], 2013.

WEBER, Max. Economia e sociedade. Brasília: EdUNB, 1991. 